Wilfrid Laurier University

Scholars Commons @ Laurier

1971

\title{
Measurement of Activity of Peroxidase Isoenzymes in Flax (Linum usitatissimum)
}

Mary Ann Fieldes

Wilfrid Laurier University, mfieldes@wlu.ca

H. Tyson

McGill University

R. Bloomberg

University of Wyoming

Follow this and additional works at: https://scholars.wlu.ca/biol_faculty

\section{Recommended Citation}

Fieldes, Mary Ann; Tyson, H.; and Bloomberg, R., "Measurement of Activity of Peroxidase Isoenzymes in Flax (Linum usitatissimum)" (1971). Biology Faculty Publications. 16.

https://scholars.wlu.ca/biol_faculty/16

This Article is brought to you for free and open access by the Biology at Scholars Commons @ Laurier. It has been accepted for inclusion in Biology Faculty Publications by an authorized administrator of Scholars Commons @ Laurier. For more information, please contact scholarscommons@wlu.ca. 


\title{
Measurement of activity of peroxidase isoenzymes in flax (Linum usitatissimum)
}

\author{
M. A. HART, ${ }^{1}$ H. Tyson, AND R. BloOMBerg ${ }^{2}$ \\ Biology Department, McGill University, Montreal, Que. \\ Received April 28, 1971
}

\begin{abstract}
HarT, M. A., H. TYSON, and R. BLOOMBERG. 1971. Measurement of activity of peroxidase isoenzymes in flax (Linum usitatissimum). Can. J. Bot. 49: 2129-2137.

Peroxidase isoenzymes may be separated on acrylamide gels and then detected by supplying the substrate in an appropriate reaction system. One such system frequently used contains guaiacol as the hydrogen donor, although this compound has certain drawbacks. Ways of circumventing these drawbacks are suggested, so that quantitative estimates of the activity of individual peroxidase isoenzymes may be obtained.
\end{abstract}

\section{Introduction}

The separation of peroxidase isoenzymes has been carried out in a number of plant species with acrylamide gel electrophoresis. Andreev and Shaw (1965) found, for example, seven anodal isoenzymes in a cultivar of flax by using disc electrophoresis with acrylamide gels. In kinetic studies on the activity of peroxidase from various sources the assay technique developed by Maehly and Chance (1954), in which guaiacol is used as the hydrogen donor, has been frequently used. This technique has also been used, in conjunction with electrophoresis, for the visualization of peroxidase isoenzymes after migration and separation, but in this latter connection the technique has drawbacks.

The Maehly and Chance technique involved the spectrophotometric tracking of the rate of the reaction between the enzyme and its hydrogen peroxide substrate, using guaiacol as the hydrogen donor in a system buffered at $\mathrm{pH}$ 7.0. The slope of the linear increase in optical density (O.D.) during the first phase of the reaction provided a measure of activity. In the later phases of the reaction, i.e. at extended periods from its start, the increase was, of course, nonlinear. Booth and Saunders (1956) suggested that the product from the oxidation of guaiacol in this reaction was essentially $2: 2$ '-dihydroxy$3: 3^{\prime}$-dimethoxyphenol. These authors also suggested that further oxidation of this product might occur, yielding a quinone, but indicated that such an additional product had not been

\footnotetext{
1 nee Fieldes.

2Present address: Division of Biochemistry, Box 3944 University Station, University of Wyoming, Laramie, Wyoming 82070 , U.S.A.
}

isolated. The color produced in the first phase of the reaction was measured at a wavelength of $470 \mathrm{~m} \mu$ by Maehly and Chance (1954); this color faded, because of partial product decomposition at room temperatures, at some point after the start of the reaction. While this fading introduced no difficulties in the measurement of rate during the first phase, it did become an important factor in using the reaction to obtain estimates of the peroxidase activity of individual peroxidase isoenzymes.

The purpose of this paper is to suggest methods, using guaiacol as the hydrogen donor, of obtaining quantitative estimates of the activity of individual peroxidase isoenzymes separated electrophoretically. Problems stemming from fading and diffusion of the guaiacol oxidation product in the gel were overcome. The effects of variation in enzyme concentration, substrate concentration, homogenate buffer $\mathrm{pH}$, and enzyme assay $\mathrm{pH}$ on the peroxidase activity of the individual isoenzymes were then investigated. The activity of isoenzymes was determined from the areas of the O.D. peaks recorded on densitometric scans of the gels containing the separated isoenzymes.

\section{Materials and Methods}

\section{(a) Plant Material}

Active extracts of peroxidase were prepared from plants of two cultivars, Royal (RO) and Mandarin (MA), of flax which had been grown in a growth chamber for 50 days with a $20-h$ daylength and 24-h temperature cycle ranging from 14 to $22^{\circ} \mathrm{C}$. The light intensity at plant apices was approximately $5000 \mathrm{ft}-\mathrm{c}$; light was supplied from a mixture of fluorescent and tungsten lamps. The plants were grown in vermiculite to which inorganic nutrients were added at intervals in a solution similar to that described by Murashige and Skoog (1962). 


\section{(b) Enzyme Extraction}

Stems with or without leaves were homogenized in $0.1 \mathrm{M}$ phosphate buffer $\left(\mathrm{KH}_{2} \mathrm{PO}_{4}, \mathrm{Na}_{2} \mathrm{HPO}_{4} \cdot 7 \mathrm{H}_{2} \mathrm{O}\right)$ at $\mathrm{pH} 5.0$ or 7.0. To the buffer used for homogenization, a Dowex resin (anion exchange $1 \times 8,200 / 400$ mesh) was in some cases added, with the aim of removing phenolic inhibitors of peroxidase, which were known to be present. The resin was equilibrated in homogenate buffer before use. These additions were on the basis of weight (resin) to volume (buffer); the detailed description of the effects of variation in buffer $\mathrm{pH}$ and resin proportion on the enzyme's activity will be reported separately. Following homogenization, the resin and tissue fragments were removed from the sample by straining through nylon mesh; the sample was then centrifuged at $45000 \times g$ for $20 \mathrm{~min}$. An alternative method of removing phenolic inhibitors was to dialyze the sample against buffer $(0.1 \mathrm{M}$, phosphate) at the same $\mathrm{pH}$ used for homogenization; this procedure was also used in some cases. The supernatant or dialysant was stored at $-17^{\circ} \mathrm{C}$ until assayed.

\section{(c) Enzyme Assay}

Guaiacol $(20 \mathrm{mM})$ was used as the hydrogen donor in the assay for peroxidase activity, with $0.1 M$ phosphate buffer $\left(\mathrm{Na}_{2} \mathrm{HPO}_{4} \cdot 7 \mathrm{H}_{2} \mathrm{O}, \mathrm{KH}_{2} \mathrm{PO}_{4}\right)$ at $\mathrm{pH} 7.0$, and 10 $\mathrm{m} M$ hydrogen peroxide substrate, which was standardized against $0.1 N \mathrm{KI}$ before use in the assays. For assays of the activity of the enzyme in plant homogenates before electrophoretic separation, the ratios chosen of buffer to guaiacol to substrate were $3: 3: 1$. In the case of isoenzymes separated on acrylamide gels, the ratios were $3: 3: 2$.

Measurements of O.D. at $470 \mathrm{~m} \mu$ were made, using a Zeiss PMQ 11 spectrophotometer equipped with automatic sample changer and recorder, at 1-min intervals up to the 5th min from the start of the reaction in the case of assays before electrophoretic separation into isoenzymes; the peroxidase activity was then expressed as the rate of increase in O.D. per minute per unit fresh weight, through the calculation of the linear regressions of O.D. on time.

For determining absorption spectra changes during the reaction, a Unicam SP 800 spectrophotometer was used. With buffer, guaiacol, and active enzyme extract in both the reference and sample cuvettes, the reaction was started in the sample cuvette by adding $\mathrm{H}_{2} \mathrm{O}_{2}$ substrate. The absorption spectra over the range 200 to $450 \mathrm{m \mu}$ were then obtained at 2.25 -min intervals from the start of the reaction. The same procedure and equipment were used to obtain absorption spectra during the course of the reaction between an individual isoenzyme, in a particular portion of an acrylamide gel track after electrophoresis, and the substrate.

For the visualization of the isoenzymes separated on gels, the gel tracks were immersed for $30 \mathrm{~min}$ in the buffer, guaiacol, $\mathrm{H}_{2} \mathrm{O}_{2}$ system detailed above, and then transferred to $7 \%$ acetic acid for $10 \mathrm{~min}$ to halt the reaction between substrate and enzyme. Both solutions were at $22^{\circ} \mathrm{C}$; the times used were optimal for the production of the maximum size of O.D. peak in the densitometric scanning of the gels which followed visualization. Gel tracks were held at $0-5^{\circ} \mathrm{C}$ in water after removal from $7 \%$ acetic acid. The scanning was carried out in the Zeiss PMQ 11 spectrophotometer equipped with a linear transporter and recorder. The recorder scans contained
O.D. peaks corresponding to the positions of the isoenzymes on the gel tracks; the areas of these peaks were measured by planimeter, and the peroxidase isoenzyme activities were then expressed in terms of square inches O.D. peak area per unit fresh weight.

\section{(d) Isoenzyme Separation}

Gels were $7 \%$ Cyanogum 41 , with a gel buffer (Tris$\mathrm{HCl}$ ) at $\mathrm{pH}$ 8.9. A Tris-glycine electrode buffer was used, with a $\mathrm{pH}$ of 8.3 . The high $\mathrm{pH}$ of the electrode and gel buffers resulted in the migration to the anode of all the isoenzymes detectable with guaiacol as the hydrogen donor. The farthest point of migration was marked by the inclusion of bromophenol blue in the sample.

An electrophoresis cell of the type described by Jordan and Raymond (1967) was used; up to 24 samples (0.05 $\mathrm{ml}$ each) could be run at the same time on the acrylamide gel slab within the cell. Upper and lower electrode buffers remained separated throughout electrophoresis. A prerun of the gel at $200 \mathrm{~V}$ for $30 \mathrm{~min}$ was made before inserting samples, in order to remove impurities which otherwise affected the subsequent densitometry. Normally, after sample migration (using a constant $400 \mathrm{~V}$ ) was complete, this slab was removed from the cell, and was immersed in the appropriate solutions for visualization of the proteins separated on it. Slicing of the gel slab into individual tracks then preceded densitometry.

A modification of the cell was, however, necessary before quantitative estimates of isoenzyme activity could be made. This was a result of diffusion of the guaiacol oxidation product in the $7 \%$ acrylamide gels used here; it meant that vertical and horizontal diffusion could take place in relation to any one point on an individual gel tract. Figure 1 illustrates the physical arrangement of the gel tracks in the gel slab, and the implications of such diffusion. Horizontal diffusion introduced an error in comparisons of isoenzyme activity between adjacent tracks, since where two isoenzymes migrated to similar points on adjacent tracks, differences between them in apparent O.D. following visualization were diminished. For any one gel track diffusion could occur between it and either or both of the gel tracks which were its immediate neighbors.

Slicing of the gel into individual tracks before any visualization procedure, solved the problem, but was technically difficult to carry out with consistent accuracy. An alternative approach was to separate the gel tracks

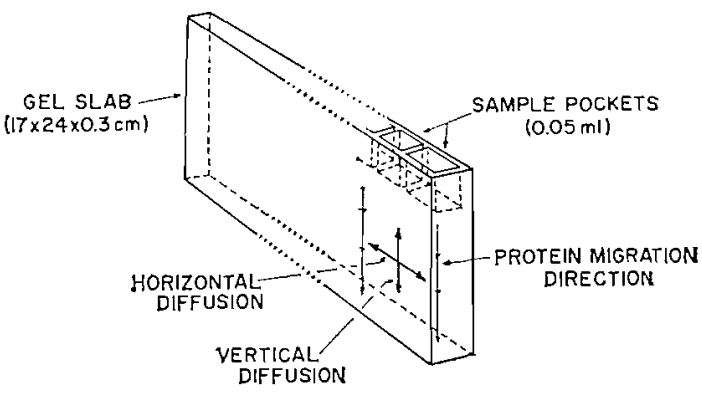

Fig. 1. Acrylamide gel slab for separation of isoenzymes: sample migration downwards from pockets at top of slab. 


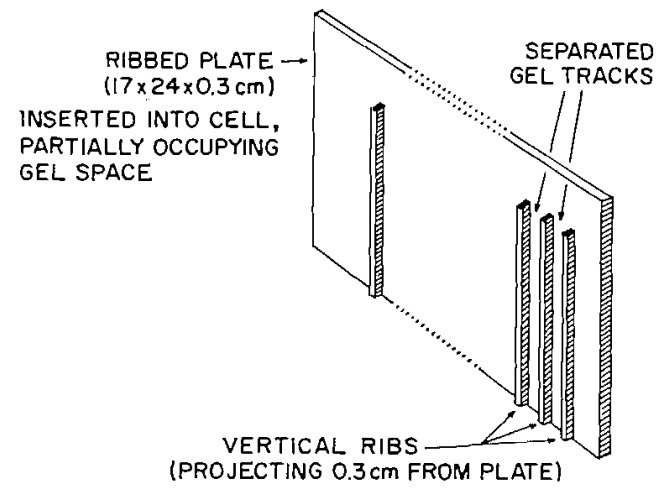

FIG. 2. Vertically ribbed plate for isolation of gel tracks within cell.

physically within the cell in a vertical plane. This was achieved by casting the gel within the cell on a plate; this plate, shown in Fig. 2, was vertically ribbed, and remained in place within the cell until the completion of migration and the dismantling of the cell. At dismantling, the individual gel tracks were extracted from the plate for staining and visualization. The separation effectively eliminated any error resulting from horizontal diffusion of reaction product, as well as horizontal migration of protein, if any, during electrophoresis. The cell was thus converted to the equivalent of the type used for disc electrophoresis, but its advantage in the simultaneous formation of the individual gel tracks with rectangular cross sections was retained.

\section{Results}

(1) Absorption Spectra in the Cuvette and in the Gel during the Reaction

The course of the reaction was followed, in terms of its adsorption spectrum, during the first phase of the reaction. The spectra obtained during the first 12 scans from 200 to $450 \mathrm{m \mu}$ after the addition of substrate are shown in Fig. 3. Accumulation of the oxidation product of guaiacol resulted in the development of absorption peaks at $243 \mathrm{m \mu}$, and (just off scale in Fig. 3 here) at $470 \mathrm{~m} \mu$. The correlation between the O.D. values over the 12 scans for any pair of these wavelengths was extremely high. The increase in O.D. with time at the two lower wavelengths was, however, somewhat slower than that at $470 \mathrm{m \mu}$.

Continuation of scanning beyond the last time point shown in Fig. 3 revealed a falloff in the rate of increase in O.D., which was most marked for O.D. values measured at $350 \mathrm{~m} \mu$ and longer wavelengths. The rate of increase at $450 \mathrm{~m} \mu$ (and $470 \mathrm{~m} \mu$ ) eventually became zero, and O.D. values at these wavelengths then began to decline. The decline coincided with the visual disappearance of the color of the reaction system in the cuvette. At the same point in time at which this decline was beginning, the O.D. values recorded at 243 and $293 \mathrm{~m} \mu$ continued to exhibit increases, although the rate of these increases was much lower than in the initial phase of the reaction. At $180 \mathrm{~min}$ from the start of the reaction, there was no indication that O.D. values for the two peaks in the ultraviolet (uv.) range of the spectrum were declining.

The use of a $295-\mathrm{m} \mu$ wavelength for densitometric measurements of peroxidase isoenzymes separated on acrylamide gels was then investigated. After electrophoresis peroxidase isoenzymes in these gels were made detectable by supplying the substrate with guaiacol and buffer at $\mathrm{pH}$ 7.0.

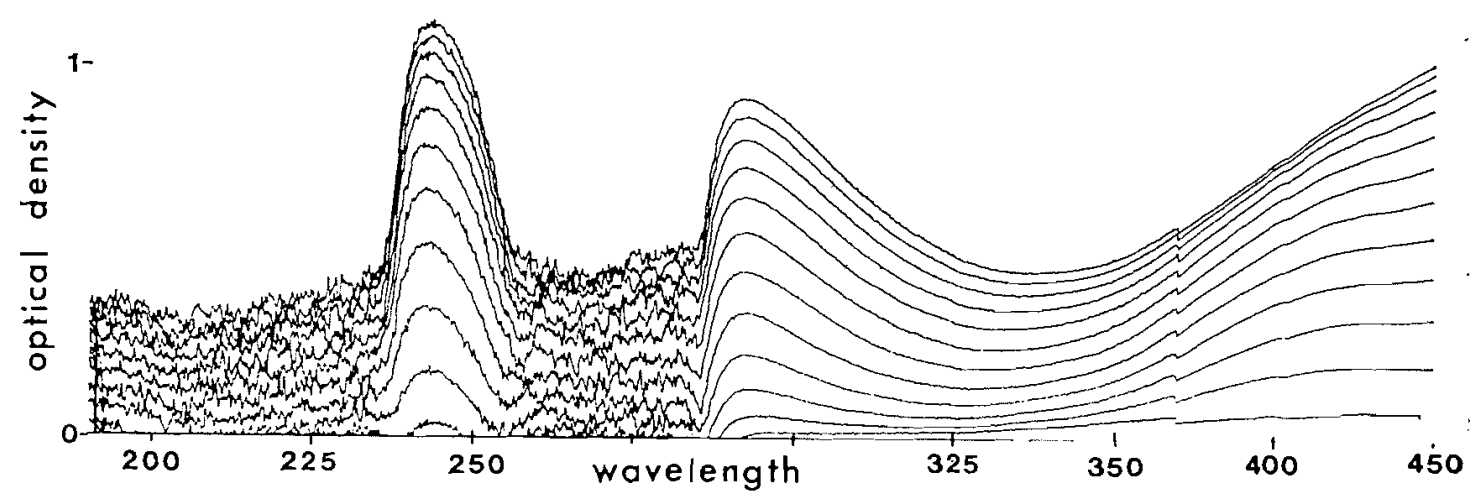

Fig. 3. Absorption spectra during reaction. Sample: buffer, guaiaco], enzyme extract, and $\mathrm{H}_{2} \mathrm{O}_{2}$ substrate. Reference: as for sample, minus $\mathrm{H}_{2} \mathrm{O}_{2}$ substrate. 
Preliminary tests with active extracts from flax plants showed that fading, and diminution of the corresponding O.D. peak areas on the recorded densitometric scans at $470 \mathrm{~m} \mu$, took place rapidly after transfer to $7 \%$ acetic acid to halt the reaction at temperatures of 20 to $25^{\circ} \mathrm{C}$. However, O.D. peaks recorded from scans at $295 \mathrm{~m} \mu$ displayed virtually no size diminution up to $180 \mathrm{~min}$ after transfer to acetic acid.

The correspondence between the oxidation product accumulated from the reaction in solution in the cuvette and the oxidation product formed within the gel was examined by scanning the gel from 200 to $450 \mathrm{~m} \mu$ following the addition of substrate. After electrophoretic migration, portions of gel containing an isoenzyme were placed in quartz cuvettes. For the reference cuvettes, the same zones from gels which had received no enzyme samples, but which had been otherwise treated in exactly the same way, were used. Scanning, after the addition of substrate to both the reference and sample cuvettes, revealed the development of two absorption peaks in the same part of the uv. range of the spectrum as was found for the reaction in solution. Thirty minutes after the start of the reaction in the gels they were transferred to $7 \%$ acetic acid, and scanning was continued over the same range. A rapid rise in O.D. values took place at 248 , 288, and 450 (also 470) $\mathrm{m} \mu$. These absorption peaks in the uv. range were slightly displaced in wavelength from those determined with the reactants in solution. Nevertheless, it may reasonably be suggested that they represented the same product as that produced by the reactants in solution.

Scanning of a reference and a sample gel before the addition of any components of the reaction system, with both reference and sample gels immersed in distilled water in the cuvettes, showed no difference in absorption over the 200 to $450 \mathrm{~m} \mu$ range. The isoenzyme present in the sample was thus undetectable until the appropriate reaction system was supplied. A check of the reference cuvette here against a cuvette with distilled water at the beginning and end of the scanning showed that no change had taken place in the reference cuvette, and that there was, therefore, no reaction occurring in the absence of the enzyme. The same finding resulted from an equivalent check of peroxidase assays of plant homogenates before electrophoresis.
At extended periods from the start of the reaction in the gel, the O.D. values from $350 \mathrm{~m} \mu$ upwards began to decline, while those in the uv. range remained constant. The decline coincided with the visual disappearance of color in the gels. Reduction of the gel temperature to 0 to $5^{\circ} \mathrm{C}$ was found to prolong the period of constant O.D. considerably beyond $180 \mathrm{~min}$ at room temperature. Holding the gels in water between 0 and $5^{\circ} \mathrm{C}$, after removal from the $7 \%$ acetic acid, made reliable, unchanged estimates of O.D. (measured at $295 \mathrm{~m} \mu$ ) peak area possible up to $60 \mathrm{~h}$ after the halting of the reaction in the gel.

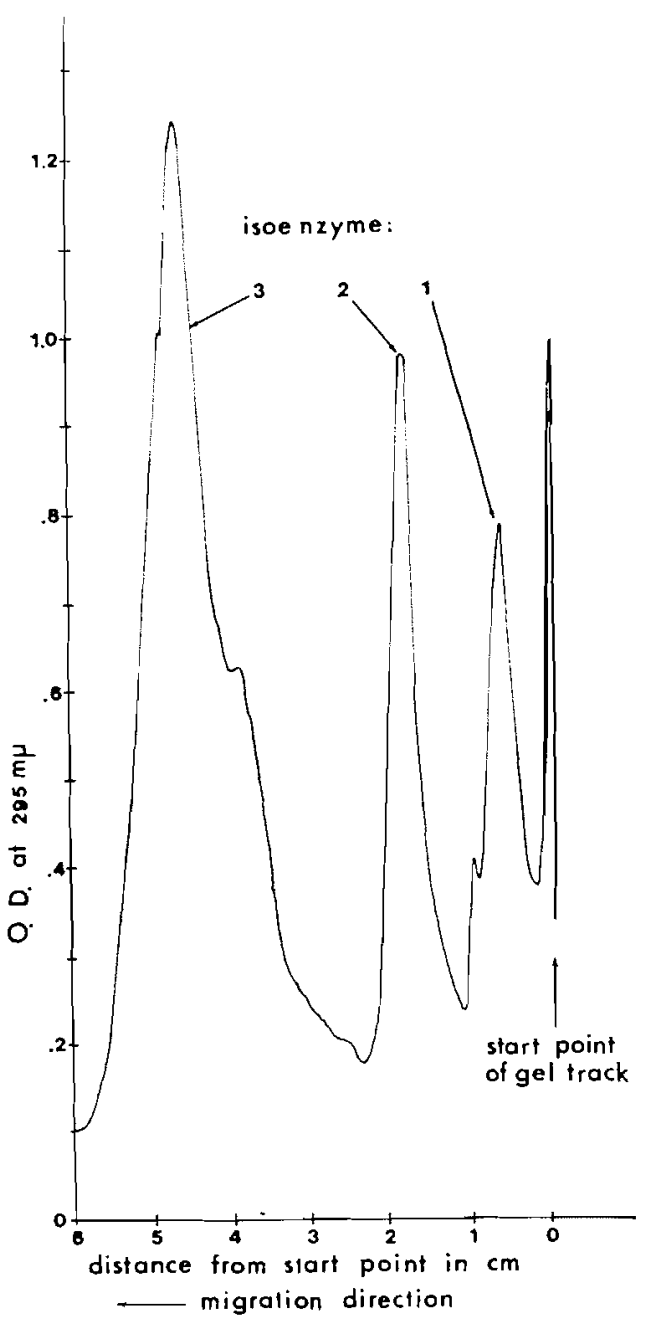

FIG. 4. Peaks recorded from spectrophotometric scan of gel track at $295 \mathrm{~m} \mu$; optical density (O.D.) output recorded. 


\section{(2) Isoenzyme Activity Measurement}

Vertical diffusion of reaction product between two isoenzymes within one gel track was found to be negligible with the samples used here. The distance between each successive isoenzyme separated within one gel track was such that error resulting from this factor was trivial; the overall distance from the starting point to marker (front) boundary was $15 \mathrm{~cm}$ in the conditions used here.

An example of the separation achieved is shown in Fig. 4. There were three main isoenzymes detected with the material here; the relative mobility of the isoenzymes shown increased from right to left of the recorded scan. The first, second, and third peaks reached O.D. values of $0.79,0.98$, and 1.25 respectively. Isoenzyme 1 (lowest relative mobility) was not completely separated from a small peak which appeared on the reverse slope of its recorded trace; there was also an indication of a shoulder on the forward slope. Such a shoulder again appeared on the forward slope of the trace for isoenzyme 3. In measuring the O.D. peak areas of the three main peaks which appeared, shoulders and incompletely separated accessory peaks were ignored. That little error was introduced by consistent application of this could be seen from the correlation between the sum of all O.D. peak areas measured for a particular sample and the peroxidase activity (gross activity) of the same sample derived from the rate of reaction in the assay before electrophoresis. Over a number of samples, the correlation between the total activity from the sum of the peak areas and that from gross activity was positive, and highly significant.

\section{(3) Effect of Variation in Sample Enzyme Con- centration on O.D. Peak Area}

The effect of variation in enzyme concentration at a constant substrate level was investigated in terms of O.D. peak area. An active enzyme extract from homogenized stem tissue of RO was used; the $0.1 \mathrm{M}$ phosphate buffer at $\mathrm{pH} 7.0$ used for homogenization contained $25 \%$ (w/v) resin. The supernatant from centrifugation represented the stock enzyme extract at concentration 1.0 in Fig. 5; dilutions with distilled water were made to produce the range of concentrations shown. Duplicate tracks were run in the electrophoresis cell for each of these concentrations. Mean O.D. peak areas for each concentration and isoenzyme are plotted in Fig. 5. Curves through each set of points were fitted after the calculation of the appropriate regressions. The analysis of variance of these data showed that there was a highly significant interaction $(P<0.01)$ between enzyme concentration and isoenzyme activity. The mean response over all isoenzymes to increasing con-

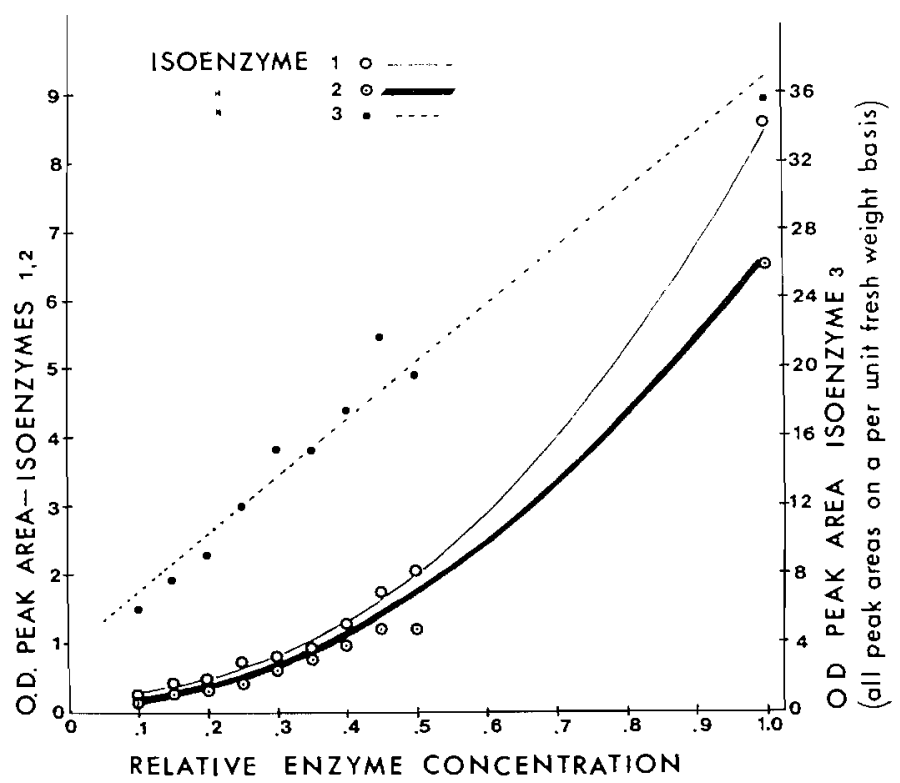

FIG. 5. Inc rease in O.D. peak area for three isoenzymes with increasing concentration of sample. 
centration was linear and highly significant ( $P$ $<0.001$ ). Analysis of the individual response of the isoenzymes to change in concentration showed that significant curvilinearity was evident in the responses of isoenzymes 1 and 2, and that their responses were similar. They were, however, markedly slower in response than isoenzyme 3 , over the range of concentrations employed here.

Assays of the gross peroxidase activity at each of the concentrations before electrophoretic separation produced the data, plotted in Fig. 6 against the corresponding total activities displayed by all isoenzymes. The correlation coefficient, $r$, was $0.98(n=10)$, and highly significant $(P<0.01)$. Over the range of concentrations used here, then, the relative activities in terms of O.D. peak areas (summed over all isoenzymes present) were a good indication of the relative activities in the samples assayed for gross activity before electrophoresis.

(4) Effect of Substrate Concentration on O.D. Peak Area

Variation in substrate concentration at a single enzyme concentration was investigated using an active enzyme extract from stem tissue of MA which had been homogenized in $0.1 M$ buffer at $\mathrm{pH} 7.0$ and then centrifuged. The strength of the $\mathrm{H}_{2} \mathrm{O}_{2}$ substrate was varied over a range above and below $10 \mathrm{~m} M$. The mean data from the duplicate tracks run at each concentration are plotted in Fig. 7. Examination of the responses of the individual isoenzymes suggested that there was a maximum in the range 0.8 to 1.4 for all three isoenzymes; the curves through each set of points were fitted after the calculation of the appropriate curvilinear regressions.

There was a general similarity between the distributions of the points and the shapes of the curves, particularly in the case of isoenzymes 1 and 2. The type of response found was complex, with indications of more than one peak in the curves for isoenzymes 1 and 2 . Other data revealed that the upward trend which occurred for 1 and 2 at the lower end of the concentration range $(0.2$ to 0.4$)$ represented a further peak in their response curve; below 0.2 both curves fell off. For isoenzyme 3 there appeared to be a maximum activity at substrate concentration 1.4 and distinct substrate inhibition at high concentra-

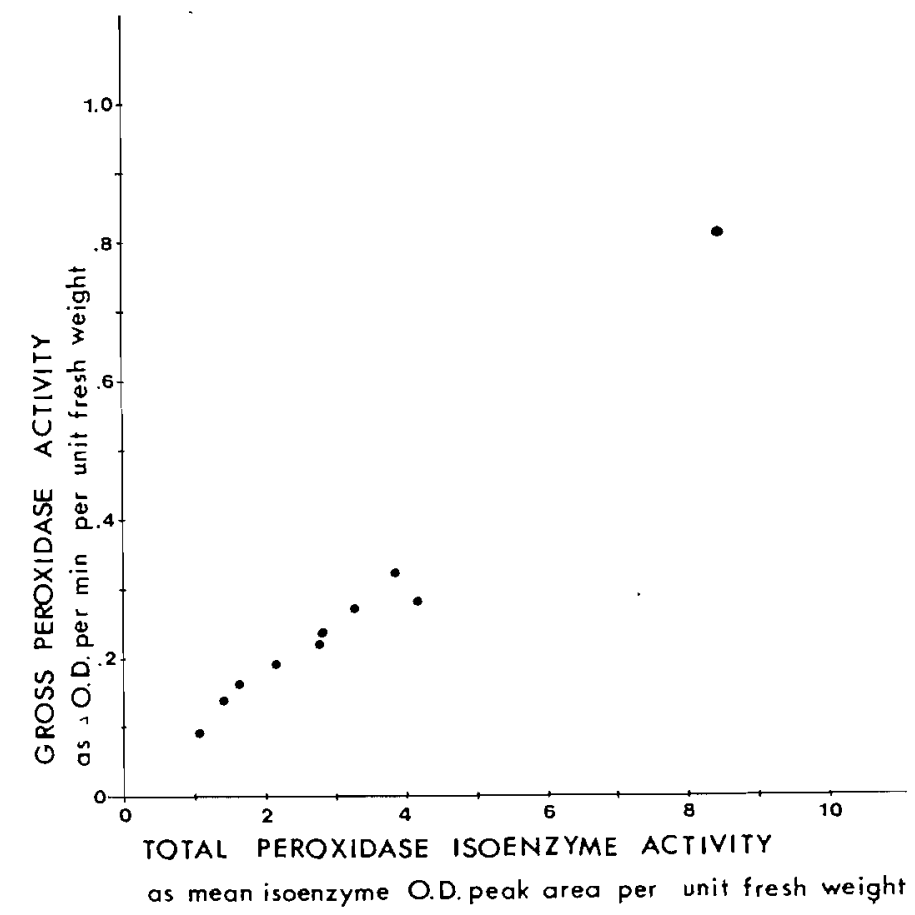

FIG. 6. Gross peroxidase activity and corresponding total isoenzyme activity, over a range of concentrations of enzyme sample. 


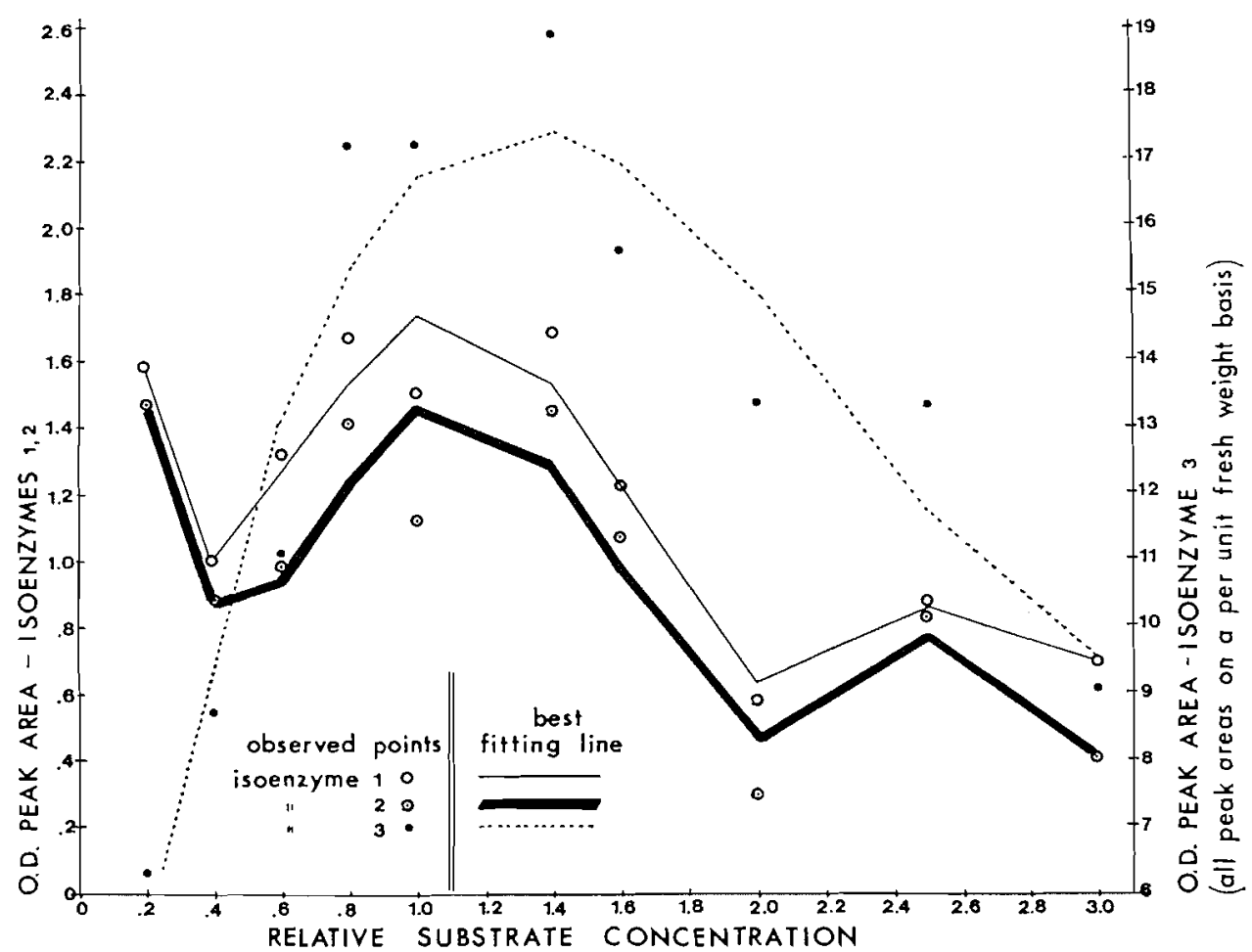

FIG. 7. Changes in O.D. peak area for three isoenzymes with increasing concentration of substrate.

TABLE 1

O.D. peak areas for pH 5.0 and 7.0 homogenate buffers with genotypes RO and MA. Triplicate gel tracks at each combination of genotype and $\mathrm{pH}$

\begin{tabular}{|c|c|c|c|c|c|}
\hline \multirow[b]{3}{*}{ Isoenzyme } & \multicolumn{4}{|c|}{ Genotype } & \multirow[b]{3}{*}{ Means } \\
\hline & \multicolumn{2}{|c|}{ RO } & \multicolumn{2}{|c|}{ MA } & \\
\hline & pH 5.0 & $\mathrm{pH} 7.0$ & pH 5.0 & $\mathrm{pH} 7.0$ & \\
\hline 1 & $\begin{array}{l}3.24 \\
1.89 \\
3.02\end{array}$ & $\begin{array}{l}2.53 \\
2.32 \\
3.03\end{array}$ & $\begin{array}{l}3.72 \\
3.37 \\
3.18\end{array}$ & $\begin{array}{l}2.12 \\
2.21 \\
2.19\end{array}$ & \\
\hline Means & 2.72 & 2.63 & 3.42 & 2.17 & 2.74 \\
\hline 2 & $\begin{array}{l}2.06 \\
1.91 \\
1.88\end{array}$ & $\begin{array}{l}2.72 \\
2.63 \\
3.08\end{array}$ & $\begin{array}{l}0.82 \\
0.97 \\
0.93\end{array}$ & $\begin{array}{l}0.65 \\
0.82 \\
0.45\end{array}$ & \\
\hline Means & 1.95 & 2.81 & 0.91 & 0.64 & 1.58 \\
\hline 3 & $\begin{array}{l}4.99 \\
5.61 \\
6.40\end{array}$ & $\begin{array}{l}9.18 \\
8.49 \\
8.90\end{array}$ & $\begin{array}{l}8.19 \\
9.92 \\
8.18\end{array}$ & $\begin{array}{l}7.57 \\
7.45 \\
9.90\end{array}$ & \\
\hline Means & 5.67 & 8.86 & 8.76 & 8.31 & 7.90 \\
\hline Overall means & 3.44 & 4.76 & 4.36 & 3.71 & \\
\hline
\end{tabular}


tions, while for 1 and 2 at low concentrations there was not the simple limiting effect due to lack of substrate that might have been expected.

\section{(5) Effect of Buffer $\mathrm{pH}$ at Homogenization on} O.D. Peak Area

Phosphate buffer, $0.1 \mathrm{M}$, was used at $\mathrm{pH} 5.0$ and at $\mathrm{pH} 7.0$ for homogenizing stem plus leaf tissue of genotypes RO and MA. Both buffers contained $15 \%(\mathrm{w} / \mathrm{v})$ resin; homogenization was followed by centrifugation. The mean data obtained for O.D. peak area are shown in Table 1. Examination of the interactions between the main factors showed that for isoenzyme 1 versus 2 there was a significant interaction with genotype $(P<0.01)$, while for isoenzymes 1 and 2 versus 3 , there were significant $(P<0.01)$ first and second order interactions with both genotype and $\mathrm{pH}$. The relationship, therefore, between the mean of 1 and 2 with 3 was not the same for genotype RO, as a result of the $\mathrm{pH}$ shift, as it was for MA. Examination of the data in Table 1 indicated the change in the relative values for isoenzyme 1 versus 2 between genotypes RO and MA, as well as the different effects of homogenate buffer $\mathrm{pH}$ on the overall activity displayed by these two genotypes. The data also revealed that for genotype $\mathrm{RO}$, buffer $\mathrm{pH}$ had a pronounced effect on the relationship between the mean of isoenzymes 1 and 2 with isoenzyme 3 . This arose from the higher activity shown by isoenzymes 2 and 3 at $\mathrm{pH} 7.0$ compared to at $\mathrm{pH} 5.0$ buffer at homogenization.

The interactions with genotype emphasized the need to limit conclusions to the situation experimentally examined, but at the same time suggested that there might well be differences in the physical-chemical attributes of the corresponding isoenzymes for these two genotypes, isoenzymes which showed but trivial differences in relative mobility.

(6) Effect of Enzyme Assay pH on O.D. Peak Area for Each Isoenzyme

Using the main stem homogenates of RO and MA (homogenate buffer $0.1 M$, pH $8.0,20 \%$ $\mathrm{w} / \mathrm{v}$ resin), the $\mathrm{pH}$ of the $0.1 \mathrm{M}$ buffer in the reaction system was adjusted to 5.0, 6.0, 7.0, and 8.0. No effect of assay $\mathrm{pH}$ was detectable on the O.D. peak areas of the isoenzymes of these particular genotypes.

\section{Discussion}

These investigations concerned enzyme preparations which had not been purified beyond the removal of the peroxidase inhibitors. Nevertheless, the data obtained demonstrated several main points, shown below.

(1) The techniques described here showed that reproducible measurements of individual peroxidase isoenzyme activity may be made directly by densitometry on gel tracks. Furthermore, there was excellent correlation between activity determined before electrophoresis (gross activity) and the sum total of isoenzyme activity. The same hydrogen donor was used for both gross and isoenzyme activity determinations; whether or not such a correlation would have been obtained, had different donors been used, is not known, but the correlation here suggested that relative activities were likely not distorted in this particular sample by the electrophoretic procedure.

Partial purification of the enzyme preparation by $\left(\mathrm{NH}_{4}\right)_{2} \mathrm{SO}_{4}$ precipitation has produced preliminary data indicating that the number of isoenzymes was unchanged and suggesting that their relative activities were unaffected by this process. Removal of inhibitor was achieved through in. clusion of an appropriate Dowex anion exchange resin at homogenization; the extent of inhibitor removal, judged by the rise in gross peroxidase activity and by the reduction in content of phenol compounds (assayed with Pauly's reagent), was largely complete at the lowest concentration $(15 \% \mathrm{w} / \mathrm{v})$ of resin used here. The evidence presented on the interrelationships between the genotype and the homogenate buffer $\mathrm{pH}$ emphasized the complexities involved in obtaining estimates of relative isoenzyme activity both within and between genotypes, complexities which may well be traceable back to the variation in physical-chemical characteristics of individual peroxidase isoenzymes.

(2) Data on the activity/substrate concentration relationships of individual isoenzymes were obtained directly from the gels by densitometry, although a wide range of substrate concentrations was required here for the detection of these relationships. The $\mathrm{pH}$ optimum for each isoenzyme may also be obtained directly from the gels by densitometry, through variation in the reaction system's $\mathrm{pH}$. The extension to examination of 
simultaneous variation in reaction system substrate concentration and $\mathrm{pH}$ through gel densitometry should be straightforward. It is still conceivable that the separation technique used, whether it be acrylamide gel electrophoresis or another method such as Sephadex column chromatography, might itself differentially alter characteristics of individual enzymes. Only comparisons of separation techniques would resolve this.

The variations in isoenzyme response to substrate concentration were not readily explainable; there are, as yet, no known functional reasons for such variations, although the spatial and developmental compartmentalization within a cell presumably provides a basis for them. Nevertheless, given techniques to determine physicalchemical characteristics of peroxidase isoenzymes, the interrelationships of genotype, environment, and developmental stage, may be explored in terms of fine control over one aspect of a cell's activities. Integration of this type of information with that on the fine structure and organization within a cell may then be expected to bring closer a sufficiently comprehensive cell description which would permit modeling and thence prediction of cellular operations.

(3) The detection of the effects of $\mathrm{pH}$ and substrate concentration, given an experimental situation involving variation in any or all of genotype, developmental stage, and environment, clearly presents practical problems. Only some of the very large number of combinations of main factors were examined here. However, determinations of relative activities of isoenzymes in a 'fixed' system, in which substrate concentration and $\mathrm{pH}$ were, in common with all other components of the technique, held constant, provide valid comparisons among, say, genotypes, developmental stages, and environments.

Genotypic control over the relative activities of members of an array of peroxidase isoenzymes, an array common, for example, to a group of genotypes, could be assessed with such a 'fixed' system. The limitations would be those applicable to any single character measurements in a group of genotypes. Examination of genotypic control over relative activities has been made for two genotypes and their $F_{1}, F_{2}$, and first backcross progeny in flax by Tyson and Bloomberg (1971). The production of all possible $F_{1}, F_{2}$, and first backcross combinations from the two parental (completely inbreeding) genotypes allowed the detection, with this 'fixed' system, of significant genetic and maternal effects on relative activity. Enlargement of this type of factorial design to include certain developmental stages and particular environments, together with measurement of isoenzyme activity over a range of levels for components in the reaction system, would be a desirable, if laborious, further step. Information on the ways in which isoenzyme activity was mediated by the genotype would be obtained, while at the same time the interrelationships between genotype and environment in the control over relative activities of an array of isoenzymes might be unraveled. The technique described here for the measurement of peroxidase isoenzyme activity provides a means of attacking such questions.

\section{Acknowledgment}

The work reported here was supported by a grant from the National Research Council of Canada, to whom thanks are extended.

ANDreev, L. N., and M. Shaw. 1965. A note on the effect of rust infection on peroxidase isozymes in flax. Can. J. Bot. 43: 1479-1483.

Booth, H., and B. C. Saunders. 1956. Studies in peroxidase action. X. J. Chem. Soc. 1956: 940-948.

JORDAN, E. M., and S. RAYMOND. 1967. Multiple analyses on a single gel electrophoresis preparation. Nature (London), 216: 78-80.

Maehly, A. C., and B. Chance. 1954. The assay of catalases and peroxidases. In Methods of biochemical analysis. Vol. 1. Pt. X. Interscience Publications, New York. pp. 358-424.

Murashige, T., and F. Skoog. 1962. A revised medium for rapid growth and bio-assays with tobacco tissue cultures. Physiol. Plant. 15: 473-497.

Tyson, H., and R. Bloomberg. 1971. Peroxidase isoenzymes in Linum. Theor. Appl. Genet. 41 : 136-141. 